Sharif University of Technology
Scientia Iranica
Transactions E: Industrial Engineering
hCIENTIA

\title{
Stepwise pricing in evaluating revenue efficiency in data envelopment analysis: A case study of power plants
}

\author{
Z. Moghaddas ${ }^{a}$, M. Vaez-Ghasemi ${ }^{b}$, F. Hosseinzadeh Lotfic ${ }^{\mathrm{c}}$, and \\ R. Farzipoor Saen ${ }^{d, *}$
}

a. Department of Mathematics, Qazvin Branch, Islamic Azad University, Qazvin, Iran.

b. Department of Mathematics, Rasht Branch, Islamic Azad University, Gilan, Iran.

c. Department of Mathematics, Science and Research, Islamic Azad University, Tehran, Iran.

d. Faculty of Business, Sohar University, Sohar, Oman.

Received 30 January 2020; received in revised form 4 May 2020; accepted 6 June 2020

\author{
KEYWORDS \\ Data Envelopment \\ Analysis (DEA); \\ Revenue efficiency; \\ Stepwise pricing; \\ Mixed integer \\ programming; \\ Big M; \\ Malmquist \\ Productivity Index \\ (MPI); \\ Piece-wise linear \\ functions.
}

\begin{abstract}
Data Envelopment Analysis (DEA) technique is widely applied for performance assessment of Decision-Making Units (DMUs). Revenue Efficiency (RE) evaluation is one of the controversial subject matters that can be performed through DEA context. The amount of production and its prices are crucial factors in the RE. The classical DEA models consider the prices fixed and known, which are not the case in the real world. Also, the classical DEA models consider linear pricing in revenue assessment. However, most of real-world problems deal with nonlinear prices. This paper evaluates the RE given the piecewise linear theory in non-competitive situations. In doing so, a stepwise pricing function is introduced that allows the prices to vary with respect to the amount of production. As an innovative idea, a more accurate mathematical modeling for the RE is proposed. A dynamic weight function is defined in the maximum revenue optimization model that no longer considers prices fixed. A case study validates our proposed model.
\end{abstract}

(C) 2022 Sharif University of Technology. All rights reserved.

\section{Introduction}

Data Envelopment Analysis (DEA) technique is a Linear Programming (LP) problem that assesses the performance of Decision-Making Units (DMUs) involving multiple inputs/outputs. DEA is used in dealing with theoretical and practical problems. The efficiency measure was first introduced by Farell [1] and then, developed by Charnes et al. [2] in the DEA framework.

\footnotetext{
*. Corresponding author. Tel.: +968 26850100; Fax: +96826720102

E-mail addresses: Zmoghaddas@qiau.ac.ir (Z. Moghaddas); mohsen.vaez@iaurasht.ac.ir (M.Vaez-Ghasemi); farhad@hosseinzadeh.ir (F.Hosseinzadeh Lotfi); farzipour@yahoo.com (R.FarzipoorSaen)
}

Following the presentation of the first DEA models, different modifications in terms of many factors/ aspects have been provided to strengthen the power of DEA. Kuosmanen and Post [3] computed relative efficiency score bounds considering upper and lower scores. They noted that these bounds reveal more accurate approximations for the relative efficiency score. They computed these bounds using LP problems. Kuosmanen and Post [4] corrected existing technical error in their previous work. Mostafaee and Saljooghi [5] considered the cost efficiency measure in the presence of inadequate price details. Chakraborty et al. [6] emphasized that the products' requirements would alter over time. Fang and Li [7] assessed the cost efficiency in the presence of uncertain prices. They utilized coneratio models in DEA with the price information and added weight bounds to the model. Also, Mozaffari 
et al. [8] introduced cost and revenue models in DEA. Ghiyasi [9] introduced inverse DEA models for assessing both cost and revenue values. Moreover, Fang and $\mathrm{Li}$ [10] considered a duality study to build theoretical attributes of envelopment and multiplier models of cost efficiency assessment assuming uncertain price. Aparicio et al. [11] demonstrated that an output-oriented version of the weighted additive model could satisfactorily ensure Revenue Efficiency (RE). They introduced an inequality to define the market output price vector. Sahoo et al. [12] claimed that firms' efficiency as well as inputs and outputs varying prices were questionable. They developed new directional measures for assessment of cost and RE. According to Aparicio et al. [13], in the case that firms face price fluctuations, the overall inefficiency measurement and decomposition would be of great importance. Cook and Zhu [14] suggested a piecewise linear pricing DEA model to evaluate the relative efficiency of DMUs. Hosseinzadeh Lotfi et al. [15] developed a modified version of the DEA model that derived suitable benchmarks for inefficient DMUs.

The RE is one of the influential indices for managers and analysts who sought new strategies for gaining more benefits. Konara et al. [16] discussed the RE in banking and emerging markets. Deng et al. [17] utilized DEA to assess the RE of Spanish hotels. Cao et al. [18] studied the decreasing marginal revenue analysis in the agriculture sector.

In the previous RE analysis by DEA models, the prices are assumed to be known and fixed for the inputs/outputs of DMUs. However, the prices are variable in real-world problems. Aroche-Reyes [19] reviewed some essential specifications of the price designation methods while considering an input-output model with focus on internal price designation procedure. Johnson and Ruggiero [20] considered a nonparametric measurement of allocative efficiency. They assumed that the output prices were endogenous. Moura [21] presented a two-sector model with two key ingredients for assessing investment shocks with endogenous relative prices. Din and Sun [22] assessed the endogenous choice of prices while taking quantities into account. Cellini et al. [23] proposed a dynamic model of price and quality competition for assessing the cause of competition on quality.

The objective of this paper is to develop a revenue efficiency DEA model to evaluate the relative efficiency of DMUs when the output prices are not fixed. In the conventional DEA models, to assess the $\mathrm{RE}$, linear pricing is assumed. However, in real-world problems, the variables have nonlinear behavior. This study assumes a non-competitive context for the RE assessment. This is the main contribution of this paper that has been considered for the first time in DEA. In doing so, here, stepwise pricing of weight function is introduced to deal with the nonlinear behavior of variables. A mixed integer LP model is developed. Then, the developed model is used for assessing RE using Malmquist Productivity Index (MPI). The MPI analyzes the progress and regress of DMUs. This paper makes the following contributions:

- This paper assumes non-competitive context for the RE assessment;

- For the first time, a DEA model is introduced to consider the nonlinear behavior of variables;

- It is shown that linear pricing does not adequately define the inherent concept of variables;

- In our new model, the prices are not assumed fixed;

- A stepwise pricing method is developed considering the theory of piece-wise linear functions;

- A case study is given.

This paper proceeds as follows: In Section 2, the DEA preliminaries are reviewed. Section 3 presents our new model. A case study is given in Section 4 . Managerial implications are discussed in Section 5. Section 6 concludes the paper.

\section{DEA preliminaries}

\subsection{Revenue Efficiency (RE)}

DEA is a mathematical method for assessing the performance of a set of DMUs. One of the hot applications of DEA is to calculate the RE. Capability of producing maximum outputs given current inputs is called RE. Here, a concise review of $\mathrm{RE}$ is given in the DEA context. DMUl is the DMU under evaluation. The used notations in this paper are as follows:

- $x_{i j}$ : The $i$ th input of $\mathrm{DMU}_{j}$

- $y_{r j}$ : The $r$ th output of $\mathrm{DMU}_{j}$

- $x_{i l}$ : The $i$ th input of $\mathrm{DMU}_{l}$

- $y_{r l}$ : The $r$ th output of $\mathrm{DMU}_{l}$

- $\lambda_{j}$ : Intensifier variables for $\mathrm{DMU}_{j}$

- $\varphi$ : The maximum increase in all outputs

- $\theta$ : The maximum decrease in all inputs

- $y_{r}$ : The $r$ th output variable

- $D^{t}\left(x_{l}^{t}, y_{l}^{t}\right): \theta^{*}$ when $\mathrm{DMU}_{l}$ and technology are in period $t$

- $D^{t+1}\left(x_{l}^{t}, y_{l}^{t}\right): \theta^{*}$ when $\mathrm{DMU}_{l}$ is in period $t$ and technology is in period $t+1$

- $D^{t}\left(x_{l}^{t+1}, y_{l}^{t+1}\right): \theta^{*}$ when $\mathrm{DMU}_{l}$ is in period $t+1$ and technology is in period $t$

- $D^{t+1}\left(x_{l}^{t+1}, y_{l}^{t+1}\right): \theta^{*}$ when DMUl and technology are in period $t+1$ 
- PL.RE.MPI $\left(x_{l}^{t+1}, y_{l}^{t+1}, x_{l}^{t}, y_{l}^{t}\right)$ : Piece-wise linear revenue Malmquist productivity index

- $M\left(x_{l}^{t+1}, y_{l}^{t+1}, x_{l}^{t}, y_{l}^{t}\right)$ : Malmquist productivity index

- $x_{i j}^{f}$ : The $i$ th input of $\mathrm{DMU}_{j}$ in period $f, f \in\{t, t+1\}$

- $y_{r j}^{f}$ : The $r$ th output of $\mathrm{DMU}_{j}$ in period $f, f \in\{t, t+$ $1\}$

- $x_{i l}^{k}$ : The $i$ th input of $\mathrm{DMU}_{l}$ in period $k, k \in\{t, t+1\}$

- $y_{r l}^{k}$ : The $r$ th output of $\mathrm{DMU}_{l}$ in period $k, k \in\{t, t+$ $1\}$

- $y_{r}^{k_{r}}$ : The $k_{r}$ th element of $r$ th output variable

- $M$ : A big scalar

- $t_{r}^{k_{r}}$ : The $k_{r}$ th element of $r$ th output for the variable $t$

- $v_{k_{r}}:$ The $k_{r}$ th binary variable

- $y_{r}^{q k_{r}}$ : The $k_{r}$ th element of the $r$ th output variable for $\mathrm{DMU}_{j}$ in period $q, q \in\{t, t+1\}$

- $y_{r j}^{f k_{r}}$ : The $k_{r}$ th element of the $r$ th output of $\mathrm{DMU}_{j}$ in period $f, f \in\{t, t+1\}$

- $y_{r j}^{k_{r}}$ : The $k_{r}$ th element of the $r$ th output of $\mathrm{DMU}_{j}$

Assume that there are $n$ DMUs with $m$ inputs and $s$ outputs that are semi-positive vectors. For each $\mathrm{DMU}_{j}$, the input and output vectors are denoted by $X_{j}=\left(x_{1 j}, x_{2 j}, \ldots, x_{m j}\right)$ and $Y_{j}=\left(y_{1 j}, y_{2 j}, \ldots, y_{s j}\right)$, respectively, for all $j$ 's.

To evaluate the DMU under evaluation $\left(\mathrm{DMU}_{l}\right)$ in constant returns to scale environment, Charnes et al. [2] proposed the following LP problem:

$$
\begin{array}{ll}
\max & \varphi \\
\text { s.t.: } & \sum_{j=1}^{n} x_{i j} \lambda_{j} \leq x_{i l} \quad i=1, \ldots, m, \\
\sum_{j=1}^{n} y_{r j} \lambda_{j} \geq \varphi y_{r l} & r=1, \ldots, s, \\
\lambda_{j} \geq 0 & j=1, \ldots, n .
\end{array}
$$

As addressed by Cooper et al. [24], RE can be obtained using the following procedure which leads to solving the following LP problem. To estimate the RE, output prices are assumed fixed and known although it is possible for them to change from one DMU to another DMU. Model (2) implies maximal revenue model, as stated by Wang et al. [25]:

$$
\begin{array}{ll}
\max & \sum_{r=1}^{s} w_{r} y_{r} \\
\text { s.t. : } & \sum_{j=1}^{n} x_{i j} \lambda_{j} \leq x_{i l} \quad i=1, \ldots, m,
\end{array}
$$

$$
\begin{array}{ll}
\sum_{j=1}^{n} y_{r j} \lambda_{j}=y_{r} & r=1, \ldots, s, \\
y_{r} \geq 0 & \mathrm{r}=1, \ldots, s, \\
\lambda_{j} \geq 0 & j=1, \ldots, n,
\end{array}
$$

where $w_{r}$ is the price of each output $y_{r}$. Each DMU produces outputs $y_{r}, r=1, \ldots, s$ at maximal revenue using inputs $x_{i}, i=1, \ldots, m$. Therefore, for each $\mathrm{DMU}_{l}$, the $\mathrm{RE}$ is defined as the ratio of its current revenue to the maximum revenue, which is the optimal solution of Model (2) as defined below:

$$
\text { Revenue efficiency }=\frac{\sum_{r=1}^{s} w_{r} y_{r l}}{\sum_{r=1}^{s} w_{r} y_{r}^{*}} .
$$

Note that Eq. (3) should be less than, or equal to, 1 and it should also be greater than 0 . The RE, considering the same level of inputs, shows the extent to which the DMU's revenue is close to the best DMU's revenue.

\subsection{Malmquist Productivity Index (MPI)}

DEA models can be used for estimating the efficiency and productivity changes over period using MPI [26]. The MPI considers two periods $(t$ and $t+1)$ and calculates efficiency variations over time. MPI can be computed by solving the following model proposed by Caves et al. [26] for evaluation of $\mathrm{DMU}_{l}$ :

$$
D\left(x_{l}, y_{l}\right)=\min \left\{\theta:\left(\theta x_{l}, y_{l}\right) \in T\right\} .
$$

Given the resultant distance function Eq. (4), consider the following input-oriented CCR (CharnesCooper-Rhodes) model:

$$
\begin{array}{ll}
D^{f}\left(x_{l}^{k}, y_{l}^{k}\right)=\min & \theta \\
\text { s.t.: } \quad \sum_{j=1}^{n} x^{f}{ }_{i j} \lambda_{j} \leq \theta x_{i l}^{k} & i=1, \ldots, m, \\
\sum_{j=1}^{n} y_{r j}^{f} \lambda_{j} \geq y_{r l}^{k} & r=1, \ldots, s, \\
\lambda_{j} \geq 0 & j=1, \ldots, n .
\end{array}
$$

Accordingly, four LP problems can be defined. Consider $l$ to be the notion of the unit under evaluation and each of $k$ and $f$ shows periods $t$ and $t+1$. For instance, to assess $\mathrm{DMU}_{l}$, let $k=t$ and $f=t+1$, $D^{t+1}\left(x_{l}^{t}, y_{l}^{t}\right)$ which shows the coordinates of $\mathrm{DMU}_{l}$ in period $t$ and technology in period $t+1$. To demonstrate the progress and regress of DMUs, Caves et al. [26] (1982) proposed MPI as given below: 


$$
\begin{aligned}
& M\left(x_{l}^{t+1}, y_{l}^{t+1}, x_{l}^{t}, y_{l}^{t}\right)= \\
& \quad\left(\frac{D^{t}\left(x_{l}^{t+1}, y_{l}^{t+1}\right) D^{t+1}\left(x_{l}^{t+1}, y_{l}^{t+1}\right)}{D^{t}\left(x_{l}^{t+1}, y_{l}^{t+1}\right) D^{t+1}\left(x_{l}^{t}, y_{l}^{t}\right)}\right)^{1 / 2}
\end{aligned}
$$

The decomposition of this index shows technical efficiency alteration and technology frontier shift while two periods are taken into account $(t$ and $t+1)$.

$$
\begin{gathered}
M\left(x_{l}^{t+1}, y_{l}^{t+1}, x_{l}^{t}, y_{l}^{t}\right)=\left(\frac{D^{t+1}\left(x_{l}^{t+1}, y_{l}^{t+1}\right)}{D^{t}\left(x_{l}^{t}, y_{l}^{t}\right)}\right) \\
\left(\frac{D^{t}\left(x_{l}^{t+1}, y_{l}^{t+1}\right) D^{t+1}\left(x_{l}^{t+1}, y_{l}^{t+1}\right)}{D^{t}\left(x_{l}^{t}, y_{l}^{t}\right) D^{t+1}\left(x_{l}^{t}, y_{l}^{t}\right)}\right)^{1 / 2}
\end{gathered}
$$

If $M\left(x_{l}^{t+1}, y_{l}^{t+1}, x_{l}^{t}, y_{l}^{t}\right)>1$, then the total productivity of DMU experiences progress. If $M\left(x_{l}^{t+1}\right.$, $\left.y_{l}^{t+1}, x_{l}^{t}, y_{l}^{t}\right)<1$, then the total productivity of DMU experiences regress. If $M\left(x_{l}^{t+1}, y_{l}^{t+1}, x_{l}^{t}, y_{l}^{t}\right)=1$, then the total productivity remains unchanged.

\section{Proposed method}

\subsection{Stepwise pricing for evaluating $R E$}

At this juncture, a new method for evaluating the $\mathrm{RE}$ is presented. To the best of our knowledge, RE has not yet been discussed so far, given nonlinear behavior of sales prices. Consider a non-competitive situation. For instance, at a power plant, it is expected that revenue be increased by producing greater electric power. If a power plant produces 9 Mega Watt per Hour (MWH) of electric power, this power will be sold for $\$ 100$ per unit for the first 5 units and $\$ 140$ per unit for the 4 units beyond the first 5 units. This is a unique case that is discussed in this paper. The existing DEA models deal with linear pricing. Linear pricing is not applicable to all situations because it may lead to inaccurate results for enterprises like power plants that should use a stepwise pricing system. The average price is not a suitable replacement as the nonlinear behavior of pricing is not considered. This paper considers the conditions in which increments in value are automatically taken into account and occur frequently in real-life situations. So far, in DEA, for calculating RE, a linear function has been considered. Linear function gives an approximate solution. Here, to assess RE, we present a model in which incremental revenue is considered.

Note that the values depend on the number of products called stepwise rating. Although the values are stable in standard RE measurement, this is not the case in real-world problems. Consider $y_{r j}$ as the $r$ th output of the $j$ th DMU. In addition, let $w_{r}$ be the value of this product. In such a situation, the producer will obtain higher revenue, if a larger number

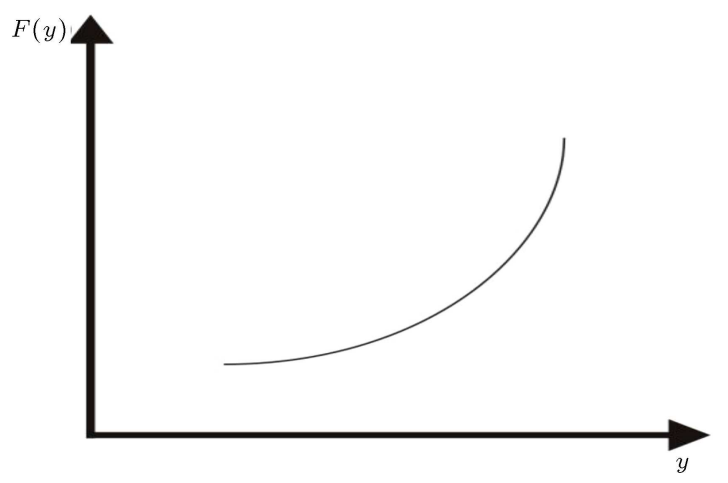

Figure 1. A convex function.

of products are produced and sold. In this case, when a stepwise rating system is contemplated, a larger number of products are sold at higher prices. To get accurate results, it is essential that a general framework be established for RE which considers the real-life market situations. Cook and Zhu [14] argued that in the multiplier DEA model, linear weighting is not adequately capable of indicating the innate behaviors of variables. They maintained that some variables had non-linear behavior and linear weighting might lead to a bias. Hosseinzadeh Lotfi et al. [15] presented a modified version of the model in the envelop form of CCR model. In Figure 1, the convex function indicates that the greater the output, the higher the revenue.

According to the piece-wise linear function theory, the estimation of this function can be enhanced by breaking down the scale of the $r$ th output into $k_{r}$ segments in which they are assumed to behave linearly in their segments (see Figure 2).

$R_{1}$ and $R_{2}$ represent sets of regular and piece-wise linear outputs with increasing magnitude, respectively. Thus, the scale of variable, which reveals piece-wise linear behavior, should be considered as $k_{r}$ ranges such as $\left[0, L_{1}\right],\left(L_{1}, L_{2}\right], \ldots,\left(L_{k r-1}, L_{k r}\right]$. Consider:

$$
t_{i}^{k_{r}}= \begin{cases}L_{k_{r}}, & \text { if } \quad k_{r}=1 \\ L_{k_{r}}-L_{k_{r}-1}, & \text { if } \quad k_{r}=2, \ldots, l_{k_{r}}\end{cases}
$$

An expert should determine the number and width of ranges. The vector of profits corresponding to $y_{r}\left(r \in R_{2}\right)$, which shows nonlinear behavior, consists of $k_{r}$ ranges as $w_{r}^{k_{r}}, k_{r}=1, \ldots, l_{k_{r}}, r \in R_{2}$, where $w_{r}^{k_{r}}<w_{r}^{k_{r+1}}, k_{r}=1, \ldots, l_{k_{r}}, r \in R_{2}$. We can represent the contribution of the $r$ th output to the weighted aggregate of all outputs in the objective function of maximal revenue model as $\sum_{k_{r}=1}^{l_{k_{r}}} w_{r}^{k_{r}} y_{r}^{k_{r}}$ instead of a single $w_{r} y_{r}$.

Assume that $y_{r}$ is the $r$ th output $\left(r \in R_{2}\right)$ which has stepwise pricing and $w_{r}$ is the corresponding vector of prices. For instance, let $k_{r}=3$ and consider three ranges for $y_{r}$ including $\left(y_{r}^{1}, y_{r}^{2}, y_{r}^{3}\right)$. We define ranges as $[0,300),[300,700)$, and $[700,1000]$ for 


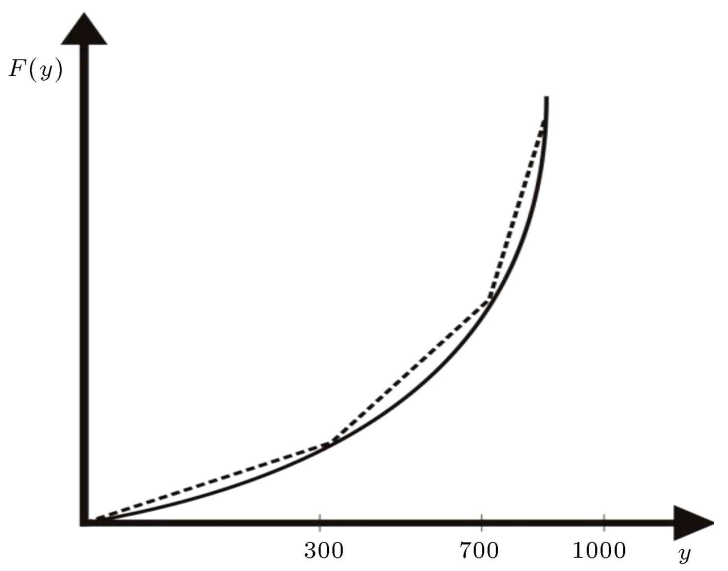

Figure 2. A convex piece-wise linear function.

$y_{r}^{1}, y_{r}^{2}$, and $y_{r}^{3}$, respectively. For $w_{r}=\left(w_{r}^{1}, w_{r}^{2}, w_{r}^{3}\right)$, consider $(650,700,750)$, respectively. In the traditional approach, $y_{r}=800$ and $w_{r}=800$ are assumed. In our approach, given the ranges and Eq. (8), $y_{r}$ should be replaced with $\left(y_{r}^{1}, y_{r}^{2}, y_{r}^{3}\right)=(300,400,100)$. Also, $w_{r}$ should be replaced with $\left(w_{r}^{1}, w_{r}^{2}, w_{r}^{3}\right)=(650,700,750)$. This conveys the meaning of stepwise pricing in which the output is sold $\$ 650$ per unit for the first range, $\$ 700$ per unit for the second range, and $\$ 750$ per unit for the third range. However, in the traditional approach, the whole 800 units of outputs are sold $\$ 800$ per unit.

Our new model (Model (9)) can find the optimal $y_{r}^{k_{r}}, k_{r}=1, \ldots, l_{k_{r}}, r \in R_{2}$, which complies with the theory of piece-wise function. It means that $y_{r}^{k_{r}}, k_{r}=$ $1, \ldots, l_{k_{r}}, r \in R_{2}$ should be a sequence of sequential values in their specified ranges. Therefore, lower ranges should be filled before higher ones are filled. The stated concepts comply with the reasoning that the scale should be divided to show the nonlinear behavior of the outputs. In Model (9), let $v_{0}=0$ and $M$ be a big positive constant. Note that $k_{r}, r \in R_{2}$ illustrates the number of intervals $\left(L_{k r-1}, L_{k r}\right]$. The binary variable $v_{k}$ forces $y_{r}^{k_{r}}$ to become zero. It is obvious that in the case that the lower ranges have not been completely met, the result would be $v_{k}=1$ in which $y_{r}^{k_{r}}$ is forced to become zero. To confine $y_{r}^{k_{r}}$ in a way that each portion of this kind of output gets a value according to Eq. (8), Constraints (a), (b), and (c) in Model (9) are added to the mathematical model. Furthermore, these variables control the lower ranges to be completed before the upper ranges. In the objective function of Model (9), it is clear that each portion of the defined output includes distinct values, which are in an increasing order and is based on its magnitude.

$\operatorname{Max} \sum_{r \in R_{1}} w_{r} y_{r}+\sum_{r \in R_{2}}\left(w_{r}^{1} y_{r}^{1}+w_{r}^{2} y_{r}^{2}+\ldots+w_{r}^{k_{r}} y_{r}^{k_{r}}\right)$

S.t.:

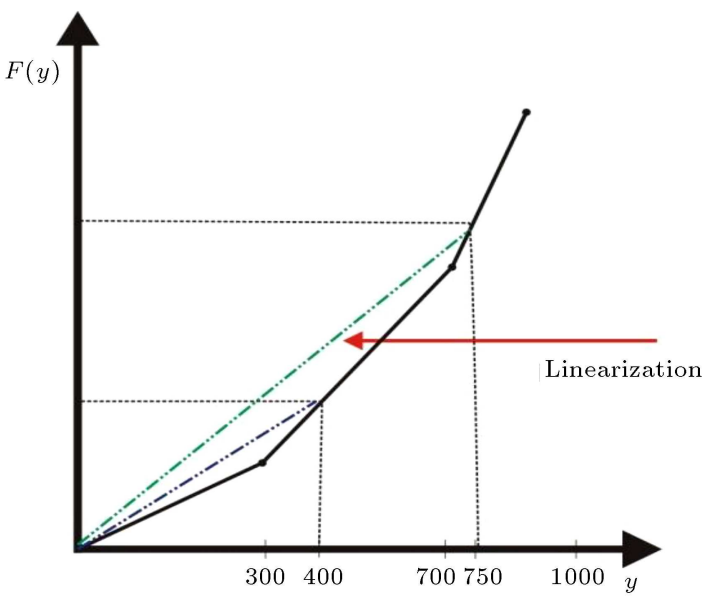

Figure 3. Linearizations of a piece-wise function.

$$
\begin{array}{ll}
\sum_{j=1}^{n} \lambda_{j} x_{i j} \leq x_{i l} & i=1, \ldots, m, \\
\sum_{j=1}^{n} \lambda_{j} y_{r j} \geq y_{r} & r \in R_{1}, \\
\sum_{j=1}^{n} \lambda_{k_{r} j} y_{r j}^{k_{r}} \geq y_{r}^{k_{r}} & r \in R_{2}, \quad k_{r}=1, \ldots, l_{k_{r}}, \\
y_{r}^{k_{r}} \leq t_{r}^{k_{r}}\left(1-v_{k_{r}-1}\right) & r \in R_{2}, \quad k_{r}=1, \ldots, l_{k_{r}}, \quad(\mathrm{a}) \\
v_{k_{r}} \leq\left(t_{r}^{k_{r}}-y_{r}^{k_{r}}\right) . M & r \in R_{2}, \quad k_{r}=1, \ldots, l_{k_{r}}, \quad(\mathrm{~b}) \\
\left(t_{r}^{k_{r}}-y_{r}^{k_{r}}\right) \leq v_{k_{r}} . M & r \in \epsilon_{2}, \quad k_{r}=1, \ldots, l_{k_{r}}, \quad(\mathrm{c}) \\
\lambda_{j} \geq 0, y_{r} \geq 0 & j=1, \ldots, n, \quad r \in R_{1}, \quad \\
\lambda_{k_{r} j} \geq 0, y_{r}^{k_{r}} \geq 0 & j=1, \ldots, n, \quad r \in R_{2}, k_{r}=1, \ldots, l_{k_{r}}, \\
v_{k_{r}} \in\{0,1\} & r \in R_{2}, \quad k_{r}=1, \ldots, l_{k_{r}} . \quad \quad(9)
\end{array}
$$

The linearization of revenue function may differ among various amounts of $y_{r}$. This is shown in Figure 3. As is seen, the linearization function differs between $y_{r}=400$ and $y_{r}=750$. Note that when $y_{r}^{(k+1)_{r}}, k_{r}=1, \ldots, l_{k_{r}}, r \in R_{2}$ has a positive value, $y_{r}^{k_{r}}, k_{r}=1, \ldots, l_{k_{r}}, r \in R_{2}$ has also a positive value. Hence, we have $w_{r}^{1} y_{r}^{1}+w_{r}^{2} y_{r}^{2}+w_{r}^{3} y_{r}^{3}$.

In Model (9), the first output has nonlinear behavior in pricing. Thus, in this model, instead of single expression $w_{1} y_{1 o}$, a linear combination like $w_{r}^{1} y_{1 l}^{1}+w_{r}^{2} y_{1 l}^{2}+\ldots+w_{r}^{l_{k_{r}}} y_{1 l}^{l_{k_{r}}}$ is replaced. Note that $l_{k r}$ shows the number of defined intervals for variations of the first output. Consider $r=2, \ldots, s$ and $r=1$ to be the sets of regular and piece-wise linear outputs, respectively. Model (9) is a mixed integer nonlinear programming as there are integer variables $v_{k r}, r=1$. Finally, a piece-wise linear RE for $\mathrm{DMU}_{l}$ is the ratio 
of piece-wise linear maximum revenue of the current revenue of $\mathrm{DMU}_{l}$ divided by the optimal solution of Model (9) which is as follows:

Revenue efficiency $=$

$$
\frac{\sum_{r \in R_{1}} w_{r} y_{r l}+\sum_{r \in R_{2}}\left(w_{r}^{1} y_{r l}^{1}+w_{r}^{2} y_{r l}^{2}+\ldots+w_{r}^{k_{r}} y_{r l}^{k_{r}}\right)}{\sum_{r \in R_{1}} w_{r} y_{r}^{*}+\sum_{r \in R_{2}}\left(w_{r}^{1} y_{r}^{* 1}+w_{r}^{2} y_{r}^{* 2}+\ldots+w_{r}^{k_{r}} y_{r}^{* k_{r}}\right)} .
$$

Theorem 3.1. Model (9) is always feasible and the objective function is bounded.

Proof: Let $\lambda_{l}=1, \lambda_{j}=0, \forall j=l, \lambda_{l}^{k r}=1, \lambda_{j}^{k r}=0$, $\forall j \neq l, \forall r=2, \ldots, s, y_{r}^{l k r}=t_{i}^{k r}, \forall r=1, \forall k_{r}=1, \ldots, l_{k r}$, $v_{0}=0, v_{k r}=0, v_{k r-1}=0, \forall r=1, k_{r}=1, \ldots, l_{k r}$. Therefore, it can be concluded that Model (9) is feasible and the objective function is bounded. After solving Model (9), the optimal solution is as $y_{2}^{*}, r=2, \ldots, s$, $y_{1}^{* k_{r}}, r=1, k_{r}=1, \ldots, l_{k_{r}}$.

Theorem 3.2. The obtained target point $\left(x_{l}, y_{r}^{*}, y_{r}^{* k_{r}}\right)$ after solving Model (9) is Pareto efficient.

Proof: An important point in DEA is that each DMU is compared with the rest of DMUs. Suppose that $\left(y_{r}^{*}, y_{r}^{* k_{r}}\right)$ is not Pareto efficient. Thus, there is a feasible solution $\left(\bar{y}_{r}, \bar{y}_{r}^{k_{r}}\right)$ that dominates $\left(y_{r}^{*}, y_{r}^{* k_{r}}\right)$. Therefore, it can be concluded that this feasible solution has a greater objective function than the obtained optimal $\left(y_{r}^{*}, y_{r}^{* k_{r}}\right)$, which is conflict with optimality of $\left(y_{r}^{*}, y_{r}^{* k_{r}}\right)$. As a result, it can be concluded that the obtained target point $\left(x_{l}, y_{r}^{*}, y_{r}^{* k_{r}}\right)$, after solving Model (9), is Pareto efficient.

Theorem 3.3. Given Model (9) and Eq. (10), at least one DMU is revenue efficient.

Proof: In Model (9), at least one inequality constraint related to the outputs should be binding. Otherwise, it is concluded that all the outputs' inequality constraints are $\sum_{j=1}^{n} \lambda_{k_{r} j} y_{r j}^{k_{r}}>y_{r}^{* k_{r}}\left(r \in R_{2}, k_{r}=1, \ldots, l_{k_{r}}\right)$. It is assumed that there is a feasible solution in which $\sum_{j=1}^{n} \lambda_{k_{r} j} y_{r_{j}}^{k_{r}} \geq \bar{y}_{r}^{k_{r}} \quad\left(r \in R_{2}, k_{r}=1, \ldots, l_{k_{r}}\right)$. In this case, $\bar{y}_{r}^{k_{r}}>y_{r}^{* k_{r}}\left(r \in R_{2}, k_{r}=1, \ldots, l_{k_{r}}\right)$, which is a contradiction. Therefore, at least for one DMU, the output inequality constraints are binding, meaning that the current revenue is equal to the maximum revenue and it is revenue efficient.

\subsection{Stepwise pricing in revenue MPI}

Here, Piece-wise Linear Revenue MPI (PLREMPI) is introduced based on Model (9). Consider periods $t$ and $t+1$. Note that $l$ is similar to the DMU under evaluation and $q$ and $f$ denote $t$ and $t+1$, respectively.
Assume $k=t$ and $f=t+1, D^{f}\left(x_{l}^{q}, y_{l}^{q}\right)=D^{t+1}\left(x_{l}^{t}, y_{l}^{t}\right)$, which shows DMUl in period $t$ while technology is considered in period $t+1$. The new model is as follows:

$D^{f}\left(x_{l}^{q}, y_{l}^{q}\right)=\operatorname{Max}$

$\sum_{r \in R_{1}} w_{r} y_{r}^{q}+\sum_{r \in R_{2}}\left(w_{r}^{1} y_{r}^{q 1}+w_{r}^{2} y_{r}^{q 2}+\ldots+w_{r}^{k_{r}} y_{r}^{q k_{r}}\right)$

S.t.:

$\sum_{j=1}^{n} \lambda_{j} x^{f}{ }_{i j} \leq x^{q}{ }_{i l} \quad i=1, \ldots, m$,

$\sum_{j=1}^{n} \lambda_{j} y_{r j}^{f} \geq y_{r}^{q} \quad r \in R_{1}$,

$\sum_{j=1}^{n} \lambda_{k_{r} j} y_{r j}^{f k_{r}} \geq y_{r}^{q k_{r}} \quad r \in R_{2}, \quad k_{r}=1, \ldots, l_{k_{r}}$,

$y_{r}^{q k_{r}} \leq t_{r}^{k_{r}}\left(1-v_{k_{r}-1}\right) \quad r \in R_{2}, \quad k_{r}=1, \ldots, l_{k_{r}}$,

$v_{k_{r}} \leq\left(t_{r}^{k_{r}}-y_{r}^{q k_{r}}\right) . M \quad r \in R_{2}, \quad k_{r}=1, \ldots, l_{k_{r}}$,

$\left(t_{r}^{k_{r}}-y_{r}^{q k_{r}}\right) \leq v_{k_{r}} . M \quad r \in R_{2}, \quad k_{r}=1, \ldots, l_{k_{r}}$,

$\lambda_{j} \geq 0, y_{r} \geq 0$

$j=1, \ldots, n, \quad r \in R_{1}$,

$\lambda_{k_{r} j} \geq 0, y_{r}^{q k_{r}} \geq 0$

$j=1, \ldots, n, \quad r \in R_{2}, k_{r}=1, \ldots, l_{k_{r}}$,

$v_{k_{r}} \in\{0,1\}$

$r \in R_{2}, k_{r}=1, \ldots, l_{k_{r}}$.

To calculate PLREMPI, Eq. (12) is used. Note that DMU is in period $t$ while technology is in period $t+1$.

$$
\begin{aligned}
& \text { PLREMPI }\left(x_{l}^{t+1}, y_{l}^{t+1}, x_{l}^{t}, y_{l}^{t}\right)= \\
& \qquad\left(\frac{D^{t}\left(x_{l}^{t+1}, y_{l}^{t+1}\right) D^{t+1}\left(x_{l}^{t+1}, y_{l}^{t+1}\right)}{D^{t}\left(x_{l}^{t}, y_{l}^{t}\right) D^{t+1}\left(x_{l}^{t}, y_{l}^{t}\right)}\right)^{1 / 2} .
\end{aligned}
$$

If the score is higher than one, then there is a progress in the productivity from period $t$ to period $t+1$. If the score is less than one, then there is a regress in the productivity from period $t$ to period $t+1$. If the score is equal to one, then there is no progress or regress in the productivity from period $t$ to period $t+1$.

\subsection{Illustrative example}

Consider five DMUs with one input $\left(I_{1}\right)$ and one output $\left(O_{1}\right)$. For the output, three ranges are considered as $o_{1}^{1}=[0,11), o_{1}^{2}=[11,17)$, and $o_{1}^{3}=[17,80)$. Numbers 
Table 1. Dataset of the example.

\begin{tabular}{ccccccc}
\hline DMUs & Current revenue & $\boldsymbol{I}_{\mathbf{1}}$ & $\boldsymbol{o}_{\mathbf{1}}^{\mathbf{1}}$ & $\boldsymbol{o}_{\mathbf{1}}^{\mathbf{2}}$ & $\boldsymbol{o}_{\mathbf{1}}^{\mathbf{3}}$ & $\boldsymbol{O}_{\mathbf{1}}$ \\
\hline 1 & 11000 & 12 & 11 & 0 & 0 & 11 \\
2 & 14600 & 24 & 11 & 3 & 0 & 14 \\
3 & 9000 & 25 & 9 & 0 & 0 & 9 \\
4 & 19700 & 17 & 11 & 6 & 1 & 18 \\
5 & 24200 & 26 & 11 & 6 & 4 & 21 \\
\hline
\end{tabular}

are in MWH. Table 1 depicts the dataset. Price vector of the output is $\left(w_{1}^{1}, w_{1}^{2}, w_{1}^{3}\right)=(1000,1200,1500)$. In the classical evaluation, the price is considered as $\$ 1000$. Note that the sum of the three ranges is equal to the initial output $\left(O_{1}\right)$. In Table 2 , the piece-wise linear evaluation of the maximum revenue is represented. Also, the results of classical maximum revenue and the optimal values of output $\left(O_{1}^{*}\right)$ are reported in Table 3 .

For $\mathrm{DMU}_{1}$, the output is 11 and the current revenue is 11000 . After evaluation by Model (9), the optimal output is 17.71 and the corresponding revenue is 19265. Given the classical revenue analysis (Model (2)), the optimal maximum revenue is 12705.88 and the optimal output is 12.71. By comparing Tables 2 and 3 , it is seen that Model (2) overestimates the outputs. Note that the outputs of $\mathrm{DMU}_{4}$ in both Models (9) and (2) are the same. However, for $\mathrm{DMU}_{5}$, Model (2) overestimates the output.

Here, we deal with outputs for presenting stepwise pricing to reach revenue evaluation in DEA context. Thus, some modifications are made to "maximum revenue" optimization model to get a new RE score. A good property of our model is that it does not present a fixed value for the outputs. Instead, given the outputs, it presents different values to get possible maximum revenue score.

\section{Case study}

Here, we wish to assess Iranian power plants. Most of the Iranian power plants are owned by government and the government sells electricity. Due to high electricity consumption in Iran, the generated electricity is insufficient. Here, 20 public power plants in Iran are assessed. Since consumption is higher than electricity generation, Iranian government faces lack of electricity. Thus, it
Table 3. Results of classical maximum revenue.

\begin{tabular}{cccc}
\hline DMUs & Maximum revenue & $\boldsymbol{I}_{\mathbf{1}}$ & $\boldsymbol{O}_{\mathbf{1}}^{*}$ \\
\hline 1 & 12705.88 & 12 & 12.71 \\
2 & 25411.76 & 24 & 25.41 \\
3 & 26470.59 & 25 & 26.47 \\
4 & 18000.00 & 17 & 18.00 \\
5 & 27529.41 & 26 & 27.53 \\
\hline
\end{tabular}

should buy electricity from private power plants and sell it to consumers at a subsidized rate. Thus, the price is considered as a penalty paid by the government for over-consumption of consumers. In some seasons, there might be periods that demand is less than supply. Thus, the government can sell the extra generated electricity to neighboring countries.

Here, the stepwise pricing for the electricity is considered in the non-competitive Iranian power generation market. Therefore, the higher the price, the greater the income. In this case, the intervals for changing amount of electricity are considered. At each interval, a specific price is considered. Note that the number and length of the intervals and corresponding prices are determined by the experts. Furthermore, assuming that fixed prices are not applicable in the real world, biased efficiency scores may be generated.

The dataset is obtained from Tavanir Management Organization [27]. Dataset dates back to the year 2004 to 2006 . The inputs and outputs are given below:

\section{$I_{1} \quad$ Capacity (MW) \\ $I_{2} \quad$ Internal usage $(\mathrm{MWH})$ \\ $I_{3} \quad$ Fuel (Tera Joule (TJ)) \\ $O_{1} \quad$ Electrical power production (MWH)}

The dataset related to 2004 is depicted in Table 4 . In Table 5, given the opinions of experts, the $O_{1}$ is divided into four ranges. There is a nonlinear relation between power generation and revenues of the power plants. Therefore, linear pricing cannot give a favorable result. However, using a stepwise rating system, a greater amount of electricity power can be sold for higher prices in noncompetitive situations.

Table 2. The results of piece-wise linear evaluation.

\begin{tabular}{ccccccc}
\hline DMUs & Maximum revenue & $\boldsymbol{I}_{\mathbf{1}}$ & $\boldsymbol{o}_{\mathbf{1}}^{\mathbf{1}}$ & $\boldsymbol{o}_{\mathbf{1}}^{\mathbf{2}}$ & $\boldsymbol{o}_{\mathbf{1}}^{\mathbf{3}}$ & Sum of output ranges \\
\hline 1 & 19265 & 12 & 11 & 6 & 0.71 & 17.71 \\
2 & 23195 & 24 & 11 & 6 & 3.33 & 20.33 \\
3 & 23705 & 25 & 11 & 6 & 3.67 & 20.67 \\
4 & 19700 & 17 & 11 & 6 & 1.00 & 18.00 \\
5 & 24200 & 26 & 11 & 6 & 4.00 & 21.00 \\
\hline
\end{tabular}


Table 4. Input and output data related to 2004 .

\begin{tabular}{ccccc}
\hline $\begin{array}{c}\text { Power plants } \\
\text { (DMUs) }\end{array}$ & $\boldsymbol{I}_{\mathbf{1}}$ & $\boldsymbol{I}_{\mathbf{2}}$ & $\boldsymbol{I}_{\mathbf{3}}$ & $\boldsymbol{O}_{\mathbf{1}}$ \\
\hline 1 & 625.88 & 241139 & 30.95308 & 3297100 \\
2 & 247.5 & 139505 & 17.00441 & 1500253 \\
3 & 50.0 & 13039 & 3.412765 & 212403 \\
4 & 1760 & 301276 & 107.1448 & 11000000 \\
5 & 1300 & 642909 & 57.30782 & 7438002 \\
6 & 1000 & 421015 & 54.61188 & 6342203 \\
7 & 240 & 85307 & 14.06063 & 1435991 \\
8 & 736 & 361080 & 42.82585 & 4341330 \\
9 & 1000 & 390708 & 46.37235 & 5134547 \\
10 & 640 & 350154 & 38.2554 & 4210280 \\
11 & 1890 & 636643 & 93.29557 & 11000000 \\
12 & 290 & 81674 & 7.886569 & 922587 \\
13 & 1280 & 588855 & 73.2442 & 7196540 \\
14 & 60 & 29698 & 4.322743 & 341402 \\
15 & 835 & 422673 & 52.77859 & 5621431 \\
16 & 1600 & 796262 & 102.4223 & 11000000 \\
17 & 600 & 271901 & 37.45617 & 3831065 \\
18 & 120 & 63050 & 7.955432 & 665887 \\
19 & 256 & 140940 & 15.76105 & 1492847 \\
20 & 1000 & 390708 & 46.37228 & 5134547 \\
\hline & & & &
\end{tabular}

Table 5. The output ranges defined for the first output.

\begin{tabular}{ccccc}
\hline DMUs & $\boldsymbol{o}_{\mathbf{1}}^{\mathbf{1}}$ & $\boldsymbol{o}_{\mathbf{1}}^{\mathbf{2}}$ & $\boldsymbol{o}_{\mathbf{1}}^{\mathbf{3}}$ & $\boldsymbol{o}_{\mathbf{1}}^{\mathbf{4}}$ \\
\hline 1 & 3000000 & 297000 & 0 & 0 \\
2 & 1500253 & 0 & 0 & 0 \\
3 & 212403 & 0 & 0 & 0 \\
4 & 3000000 & 2000000 & 2000000 & 4000000 \\
5 & 3000000 & 2000000 & 2000000 & 438002 \\
6 & 3000000 & 2000000 & 1342203 & 0 \\
7 & 1435991 & 0 & 0 & 0 \\
8 & 3000000 & 1341330 & 0 & 0 \\
9 & 3000000 & 2000000 & 134547 & 0 \\
10 & 3000000 & 1210280 & 0 & 0 \\
11 & 3000000 & 2000000 & 2000000 & 4000000 \\
12 & 922587 & 0 & 0 & 0 \\
13 & 3000000 & 2000000 & 2000000 & 196540 \\
14 & 341402 & 0 & 0 & 0 \\
15 & 3000000 & 2000000 & 621431 & 0 \\
16 & 3000000 & 2000000 & 2000000 & 4000000 \\
17 & 3000000 & 831065 & 0 & 0 \\
18 & 665887 & 0 & 0 & 0 \\
19 & 1492847 & 0 & 0 & 0 \\
20 & 3000000 & 2000000 & 134547 & 0 \\
\hline & & & &
\end{tabular}

Table 6. The efficiency scores obtained from Model (9).

\begin{tabular}{cccccc}
\hline DMUs & PL-RE & RE & DMUs & PL-RE & RE \\
\hline 1 & 0.400 & 0.891 & 11 & 1.000 & 1.000 \\
2 & 0.180 & 0.881 & 12 & 0.110 & 0.917 \\
3 & 0.031 & 0.661 & 13 & 1.000 & 0.866 \\
4 & 1.000 & 1.000 & 14 & 0.020 & 0.828 \\
5 & 0.982 & 1.000 & 15 & 0.750 & 0.985 \\
6 & 0.881 & 1.000 & 16 & 1.000 & 1.000 \\
7 & 0.170 & 0.931 & 17 & 0.480 & 0.947 \\
8 & 0.541 & 0.901 & 18 & 0.083 & 0.807 \\
9 & 0.670 & 0.905 & 19 & 0.180 & 0.865 \\
10 & 0.531 & 0.991 & 20 & 0.670 & 0.904 \\
\hline
\end{tabular}

Current DEA models cannot consider stepwise pricing in revenue evaluation. Thus, previous DEA models may produce erroneous results.

Given Eq. (8) and to apply our model, four output ranges are taken into consideration:

$$
\begin{aligned}
& O_{1}^{1}=[0,3], \quad O_{1}^{2}=(3,5], \\
& O_{1}^{3}=(5,7], \quad \text { and } \quad O_{1}^{4}=(7, \infty) .
\end{aligned}
$$

The numbers are in MWH. For example, as is depicted in Table 4, the output of $\mathrm{DMU}_{1}$ is 3297100 . The intervals of this output, given in Eq. (13), are defined as $(3000000,297100,0,0)$. The corresponding prices for each of the defined intervals are 1000, 1200, 1500 , and 1800, respectively (100 Rials). Hence, it can be said that we deal with a stepwise pricing system.

Table 6 shows classical RE and Piece-wise LinearRevenue Efficiency (PL-RE). The results are obtained by solving Model (9) and using Eq. (10). GAMS software is employed to solve the problem. As is seen in Table 6, compared with the results of classical RE evaluations, the results of PL-RE might be increasing, decreasing, or unchanged. This could be similar to the classical RE findings in which outputs follow a nonlinear behavior. It is clear that our proposed model yields substantial improvement in the RE measurement.

There is a difference between the results of Models (2) and (9). Generally, the efficiency scores obtained from the piece-wise linear DEA analysis can be either lower or higher than the standard DEA peers. In the results, compared with the standard RE model, some DMUs have higher efficiency scores, while some have lower efficiency scores. The results are obtained using GAMS software.

Figure 4 compares the results of $\mathrm{RE}$ and PLRE. Now, consider the output of $\mathrm{DMU}_{5}$ (7438002) as indicated by (3000000, 2000000, 2000000, 438002). According to the experts' opinions, the corresponding prices are in an increasing order $(1000,1200,1500$, and 1800). The PL-RE for $\mathrm{DMU}_{5}$ is 0.98 . This measure 


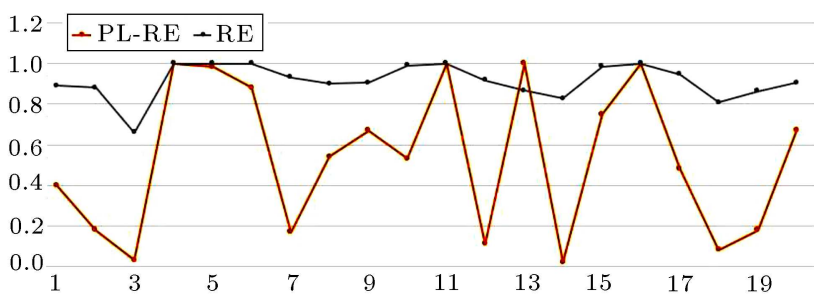

Figure 4. The results of Revenue Efficiency (RE) and Piece-wise Linear Revenue Efficiency (PL-RE).

is derived from dividing the revenue obtained from the current level of the output by the result of Eq. (8). It shows the best possible revenue for $\mathrm{DMU}_{5}$. The result of Eq. (8) for $\mathrm{DMU}_{5}$ is $(3000000,2000000,2000000$, and 218496.09). Given the defined values for each of these ranges, the obtained revenue is 9188403600 . However, by multiplying the amount of each interval by the vector value, we obtain 9057003000 . In addition, by dividing 9057003000 by 9188403600 , the PL-RE is obtained. This measure indicates a crucial debate that $\mathrm{DMU}_{5}$ can increase its output given the same inputs. This is the most important result that can be obtained from peer revenue evaluation. Another important finding is that the managers can understand the capability of the system better for producing products.

At this juncture, let us contemplate the classical method for deriving RE. The RE score for $\mathrm{DMU}_{5}$ in the classical method is equal to 1 . This score is obtained from Eq. (10) by dividing the revenue obtained from the current output (7438002000) by the best possible revenue for $\mathrm{DMU}_{5}$ which is obtained from Model (9).
This measure demonstrates that the obtained output is the best for $\mathrm{DMU}_{5}$ and it cannot produce more output given the similar level of inputs. However, by using Model (2) and Expression (3), the RE score of $\mathrm{DMU}_{17}$ is 0.48 . This score shows that $\mathrm{DMU}_{17}$ can increase its output. Given the classical Model (2) and Eq. (3), this measure is obtained by dividing the revenue obtained from the current output by the best possible revenue for $\mathrm{DMU}_{17}$. In piece-wise linear pricing, the revenue obtained from the current output is 3997278000 and the best possible revenue for $\mathrm{DMU}_{17}$ is 3997278000 . Therefore, by dividing these two numbers, we get 1 . In Table 6, the optimal solution of Eq. (8) is reported. There is a significant difference between the two sets of results. The convex function, as illustrated in Figure 1, denotes an increasing function. To estimate the convex function by a linear function, the characteristics of the convex function cannot be displayed precisely. Thus, the results are inaccurate. However, estimating the convex function by a piece-wise linear convex function leads to more accurate results. A similar analysis can be repeated for 2005 and 2006 . The dataset is reported in Table 7 .

The optimal maximum piece-wise linear revenue and efficiency scores are depicted in Table 8. In Table 8, the optimal maximum piece-wise linear revenues for 2004, 2005, and 2006 are listed.

Table 9 shows the PL-RE scores in 2005 and 2006. For example, in 2004, the optimal values of $\mathrm{DMU}_{1}$ for each divided range are $(3000000,2000000$, 2000000 , and 0). The sum of ranges is 7000000 . Upon comparing the obtained target for the output

Table 7. The dataset (2005 and 2006).

\begin{tabular}{|c|c|c|c|c|c|c|c|c|}
\hline \multirow[b]{2}{*}{ DMUs } & \multicolumn{4}{|c|}{2005} & \multicolumn{4}{|c|}{2006} \\
\hline & $I_{1}$ & $I_{2}$ & $I_{3}$ & $O_{1}$ & $I_{1}$ & $I_{2}$ & $I_{3}$ & $O_{1}$ \\
\hline 1 & 260 & 615989 & 3.20 & 2222273 & 1465 & 606125 & 5.780 & 7528574 \\
\hline 2 & 241 & 725654 & 99.340 & 2692987 & 1584 & 54636 & 45.764 & 9722169 \\
\hline 3 & 365 & 285942 & 57.230 & 7904814 & 1271 & 889503 & 84.562 & 9163596 \\
\hline 4 & 627 & 652939 & 46.300 & 1571045 & 959 & 440922 & 45.873 & 4177877 \\
\hline 5 & 676 & 323994 & 38.987 & 6629453 & 240 & 759745 & 43.673 & 4448964 \\
\hline 6 & 442 & 352884 & 92.345 & 6789916 & 279 & 865304 & 12.673 & 6077669 \\
\hline 7 & 1538 & 41414 & 53.456 & 2165922 & 884 & 401264 & 98.563 & 6948107 \\
\hline 8 & 1088 & 230039 & 100.453 & 2229153 & 1415 & 312014 & 34.674 & 9642639 \\
\hline 9 & 1931 & 381196 & 36.765 & 6651760 & 1614 & 972120 & 45.632 & 7206031 \\
\hline 10 & 1978 & 320838 & 38.987 & 11480340 & 596 & 693166 & 89.234 & 4577178 \\
\hline 11 & 1541 & 584695 & 95.980 & 5699805 & 961 & 349921 & 13.452 & 7320412 \\
\hline 12 & 835 & 288844 & 13.456 & 1216457 & 690 & 468501 & 103.452 & 2317777 \\
\hline 13 & 851 & 203257 & 7.849 & 9776371 & 1241 & 429415 & 76.34 & 6034480 \\
\hline 14 & 1080 & 23631 & 62.56 & 11468004 & 345 & 26308 & 57.836 & 1285188 \\
\hline 15 & 384 & 350528 & 93.456 & 2056659 & 805 & 250166 & 37.893 & 6158195 \\
\hline 16 & 1123 & 740735 & 85.912 & 6751574 & 118 & 438411 & 16.75 & 3046098 \\
\hline 17 & 1042 & 311695 & 76.843 & 11575914 & 1189 & 456237 & 97.543 & 4964059 \\
\hline 18 & 1540 & 53701 & 18.453 & 8448269 & 1345 & 329387 & 48.341 & 2964572 \\
\hline 19 & 981 & 104550 & 19.457 & 846810 & 263 & 386149 & 15.894 & 2866023 \\
\hline 20 & 1931 & 381196 & 36.757 & 6651760 & 1614 & 972120 & 45.602 & 7206031 \\
\hline
\end{tabular}


Table 8. Optimal maximum piece-wise linear revenues for each year.

\begin{tabular}{cccc}
\hline DMUs & $\mathbf{2 0 0 4}$ & $\mathbf{2 0 0 5}$ & $\mathbf{2 0 0 6}$ \\
\hline 1 & 15600000000.00 & 2222273000.0000 & 9351433200.0000 \\
2 & 1500253000.000 & 2692987000.0000 & 13299904200.000 \\
3 & 219488279.0000 & 10028665200.000 & 12294472800.000 \\
4 & 15600000000.00 & 12184718052.617 & 7386842138.6930 \\
5 & 9188403600.000 & 12473798836.527 & 4738756800.0000 \\
6 & 7413304500.000 & 10780237519.055 & 7016503500.0000 \\
7 & 1435991000.000 & 15621206779.588 & 8322160500.0000 \\
8 & 4609596000.000 & 16581585566.974 & 13156750200.000 \\
9 & 5601820500.000 & 16245741346.381 & 13298200293.057 \\
10 & 4452336000.000 & 16464612000.000 & 7700624605.7850 \\
11 & 15600000000.00 & 16636645200.000 & 8976741600.0000 \\
12 & 922587000.0000 & 13372816127.548 & 7512657957.4250 \\
13 & 8753772000.000 & 13397467800.000 & 11639050395.669 \\
14 & 362147158.0 .00 & 16442407200.000 & 1285188000.0000 \\
15 & 6332146500.000 & 10214118109.897 & 7137292500.0000 \\
16 & 15600000000.00 & 16636645200.000 & 3055317600.0000 \\
17 & 3997278000.000 & 16636645200.000 & 11178711052.722 \\
18 & 725157139.0000 & 11006884200.000 & 12521705809.707 \\
19 & 1537630716.000 & 1093548938.9070 & 2866023000.0000 \\
20 & 5601820500.000 & 16245741346.378 & 13298200293.042 \\
\hline & & &
\end{tabular}

(7000000) with its initial amount (3297100), we find out that $\mathrm{DMU}_{1}$ should increase its output to become efficient. In 2005, the initial output is 2222273 and the obtained output target is 7500465.270 . The divided ranges are $(3000000.000,2000000.000,2000000.000$, and 500465.27). For the output, we can increase the output by $3.37 \%$. In 2006 , the target output is 7528574 and compared with the initial amount (7528574), it is fixed.

As another example, consider $\mathrm{DMU}_{8}$ In 2004, the obtained target for each of the divided outputs is $(3000000,2000000,2000000$, and 500465.27) whose sum is 7500465.27 . Note that the initial output is $4341330\left(3000000,1341330,0\right.$, and 0). Thus, $\mathrm{DMU}_{8}$ can increase its output by $1.73 \%$. In $2005, \mathrm{DMU}_{8}$ can increase its output by $5.17 \%$. Its initial output and target are 2229153 and 11545325.31 , respectively. In 2006 , it cannot increase its output as its initial output and target are 9642639 and 9642639 , respectively.

Therefore, to assess the performance of the power plants during three years, the MPI can be utilized. Note that the MPI can determine situations where there is no change.

In Table 10, the optimal maximum piece-wise linear output resulting from Model (9) is listed. The optimal maximum piece-wise linear outputs for $\mathrm{DMU}_{1}$, $\mathrm{DMU}_{8}, \mathrm{DMU}_{11}, \mathrm{DMU}_{13}$, and $\mathrm{DMU}_{15}$ are depicted in Table 10 as instances. The ranges are obtained by
Table 9. Piece-wise linear revenue efficiency scores in 2005 and 2006.

\begin{tabular}{cccccc}
\hline DMUs & $\mathbf{2 0 0 5}$ & $\mathbf{2 0 0 6}$ & DMUs & $\mathbf{2 0 0 5}$ & $\mathbf{2 0 0 6}$ \\
\hline 1 & 0.24 & 1.00 & 11 & 0.39 & 1.00 \\
2 & 0.27 & 1.00 & 12 & 0.09 & 0.26 \\
3 & 1.00 & 1.00 & 13 & 1.00 & 0.60 \\
4 & 0.13 & 0.49 & 14 & 1.00 & 0.10 \\
5 & 0.63 & 0.54 & 15 & 0.20 & 0.85 \\
6 & 0.75 & 0.78 & 16 & 0.48 & 0.34 \\
7 & 0.14 & 0.93 & 17 & 1.00 & 0.48 \\
8 & 0.13 & 1.00 & 18 & 1.00 & 0.24 \\
9 & 0.52 & 0.66 & 19 & 0.06 & 0.32 \\
10 & 1.00 & 0.55 & 20 & 0.52 & 0.67 \\
\hline
\end{tabular}

Eq. (8). Similarly, we can obtain the results for other DMUs. The optimal values of the piece-wise linear output $o_{1}$ are reported in Table 10. Moreover, the summation of these values for years 2004, 2005, and 2006 is calculated. These results are then used in Eq. (10) as $y^{*}$ for calculating the PL-RE for years 2004, 2005 , and 2006.

Knowing progress and regress of DMUs in different periods helps decision-makers to better recognize the shortcomings of DMUs. After obtaining the optimal objective function of Model (11), using Eq. (12), the MPI is calculated. The MPIs are listed in Tables 
Table 10. Optimal maximum piece-wise linear output.

\begin{tabular}{ccccccc}
\hline & Outputs & $\mathbf{D M U}_{\mathbf{1}}$ & $\mathbf{D M U}_{\mathbf{8}}$ & $\mathbf{D M U}_{\mathbf{1 1}}$ & $\mathbf{D M U}_{\mathbf{1 3}}$ & $\mathbf{D M U}_{\mathbf{1 5}}$ \\
\hline \multirow{2}{*}{2004} & $o_{1}^{1}$ & 3000000 & 3000000 & 3000000 & 3000000 & 3000000 \\
& $o_{1}^{2}$ & 2000000 & 2000000 & 2000000 & 2000000 & 2000000 \\
& $o_{1}^{3}$ & 2000000 & 2000000 & 2000000 & 2000000 & 2000000 \\
& $o_{1}^{4}$ & 0 & 67354.51 & 4000000 & 196540 & 3272.77 \\
& Sum & 7000000 & 7067354.51 & 11000000 & 7196540 & 7003272.77 \\
& $o_{1}^{1}$ & 3000000 & 3000000 & 3000000 & 3000000 & 3000000 \\
& $o_{1}^{2}$ & 2000000 & 2000000 & 2000000 & 2000000 & 2000000 \\
& $o_{1}^{3}$ & 2000000 & 2000000 & 2000000 & 2000000 & 2000000 \\
& $o_{1}^{4}$ & 500465.27 & 4545325.31 & 4575914 & 2776371 & 1007843.39 \\
& Sum & 7500465.27 & 11545325.31 & 11575914 & 9776371 & 8007843.39 \\
& $o_{1}^{1}$ & 3000000 & 3000000 & 3000000 & 3000000 & 3000000 \\
& $o_{1}^{2}$ & 2000000 & 2000000 & 2000000 & 2000000 & 2000000 \\
& $o_{1}^{3}$ & 2000000 & 2000000 & 2000000 & 2000000 & 2000000 \\
& $o_{1}^{4}$ & 528574 & 2642639 & 320412 & 1799472.44 & 0 \\
& Sum & 7528574 & 9642639 & 7320412 & 8799472.44 & 7000000 \\
\hline
\end{tabular}

Table 11. Malmquist Productivity Index (MPI) comparing the year 2004 with 2005.

\begin{tabular}{cccccc}
\hline DMU & $\boldsymbol{D}^{\mathbf{2 0 0 4}}\left(\boldsymbol{x}_{l}^{\mathbf{2 0 0 4}}, \boldsymbol{y}_{l}^{\mathbf{2 0 0 4}}\right)$ & $\boldsymbol{D}^{\mathbf{2 0 0 5}}\left(\boldsymbol{x}_{l}^{\mathbf{2 0 0 5}}, \boldsymbol{y}_{l}^{\mathbf{2 0 0 5}}\right)$ & $\boldsymbol{D}^{\mathbf{2 0 0 4}}\left(\boldsymbol{x}_{l}^{\mathbf{2 0 0 5}}, \boldsymbol{y}_{l}^{\mathbf{2 0 0 5}}\right)$ & $\boldsymbol{D}^{\mathbf{2 0 0 5}}\left(\boldsymbol{x}_{l}^{\mathbf{2 0 0 4}}, \boldsymbol{y}_{l}^{\mathbf{2 0 0 4}}\right)$ & $\begin{array}{c}\text { MPI } \\
(\mathbf{2 0 0 4}-\mathbf{2 0 0 5})\end{array}$ \\
\hline 1 & 0.3996 & 0.2389 & 0.202 & 0.142 & 0.65 \\
2 & 0.1786 & 0.2685 & 0.09 & 0.173 & 1.696 \\
3 & 0.0253 & 1 & 0.013 & 0.643 & 44.612 \\
4 & 1 & 0.1289 & 0.938 & 0.101 & 0.118 \\
5 & 0.9857 & 0.6289 & 0.552 & 0.503 & 0.762 \\
6 & 0.8825 & 0.75 & 0.446 & 0.518 & 0.994 \\
7 & 0.171 & 0.1387 & 0.086 & 0.139 & 1.142 \\
8 & 0.541 & 0.1344 & 0.277 & 0.143 & 0.358 \\
9 & 0.6669 & 0.5154 & 0.337 & 0.537 & 1.11 \\
10 & 0.53 & 1 & 0.268 & 1.055 & 2.728 \\
11 & 1 & 0.3877 & 0.938 & 0.413 & 0.413 \\
12 & 0.1098 & 0.091 & 0.055 & 0.078 & 1.08 \\
13 & 1 & 1 & 0.526 & 0.859 & 1.278 \\
14 & 0.0219 & 1 & 0.021 & 1.054 & 48.428 \\
15 & 0.7533 & 0.2014 & 0.381 & 0.132 & 0.304 \\
16 & 1 & 0.4825 & 0.938 & 0.515 & 0.515 \\
17 & 0.4759 & 1 & 0.242 & 1.066 & 3.046 \\
18 & 0.0793 & 1 & 0.04 & 0.706 & 14.91 \\
19 & 0.1777 & 0.0563 & 0.09 & 0.054 & 0.438 \\
\hline
\end{tabular}

11 and 12. Upon comparing the years 2004 and 2005 as well as the years 2005 and 2006, as depicted in Tables 11 and 12, some DMUs have regressed while some have progress. Note hat our method deals with the nonlinear behavior of variables and it affects progress and regress of DMUs during periods.

\section{Managerial implications}

Energy consumption reduction is an important issue.
This issue should be accepted as a principle in society in both energy production and consumption. An important measure that can help producers to evaluate their performances is the RE score. This study addressed the main shortcoming of the classical RE, which is the fixed price assumption. Also, the previous DEA models are modified to face the stepwise pricing. The proposed DEA model functions based on mixed integer programming and the big $M$ technique. In the case study, it is shown that the results of our model are different 
Table 12. Malmquist Productivity Index (MPI) comparing the year 2005 with 2006.

\begin{tabular}{|c|c|c|c|c|c|}
\hline DMU & $D^{2005}\left(x_{l}^{2005}, y_{l}^{2005}\right)$ & $D^{2006}\left(x_{l}^{2006}, y_{l}^{2006}\right)$ & $D^{2005}\left(x_{l}^{2006}, y_{l}^{2006}\right)$ & $D^{2006}\left(x_{l}^{2005}, y_{l}^{2005}\right)$ & $\begin{array}{c}\text { MPI } \\
(2005-2006)\end{array}$ \\
\hline 1 & 0.2389 & 1.0000 & 0.1670 & 0.5620 & 3.7530 \\
\hline 2 & 0.2685 & 1.0000 & 0.2040 & 0.7990 & 3.8170 \\
\hline 3 & 1.0000 & 1.0000 & 0.7540 & 0.7390 & 0.9900 \\
\hline 4 & 0.1289 & 0.4917 & 0.1180 & 0.2650 & 2.9270 \\
\hline 5 & 0.6289 & 0.5402 & 0.5900 & 0.2850 & 0.6440 \\
\hline 6 & 0.7500 & 0.7816 & 0.6080 & 0.4220 & 0.8500 \\
\hline 7 & 0.1387 & 0.9271 & 0.1630 & 0.5000 & 4.5310 \\
\hline 8 & 0.1344 & 1.0000 & 0.1680 & 0.7910 & 5.9250 \\
\hline 9 & 0.5154 & 0.6596 & 0.6300 & 0.5270 & 1.0350 \\
\hline 10 & 1.0000 & 0.545 & 1.2380 & 0.2940 & 0.3600 \\
\hline 11 & 0.3877 & 1.0000 & 0.4850 & 0.5400 & 1.6940 \\
\hline 12 & 0.0910 & 0.2582 & 0.0910 & 0.1390 & 2.0790 \\
\hline 13 & 1.0000 & 0.5973 & 1.0070 & 0.4180 & 0.4980 \\
\hline 14 & 1.0000 & 0.0967 & 1.2360 & 0.0770 & 0.0780 \\
\hline 15 & 0.2014 & 0.8497 & 0.1550 & 0.4290 & 3.4210 \\
\hline 16 & 0.4825 & 0.3404 & 0.6040 & 0.1840 & 0.4630 \\
\hline 17 & 1.0000 & 0.4792 & 1.2510 & 0.3220 & 0.3510 \\
\hline 18 & 1.0000 & 0.2368 & 0.8280 & 0.1780 & 0.2260 \\
\hline 19 & 0.0563 & 0.3193 & 0.0640 & 0.1720 & 3.9170 \\
\hline 20 & 0.5156 & 0.6598 & 0.6332 & 0.5272 & 1.0354 \\
\hline
\end{tabular}

Table 13. The results of our new approach.

\begin{tabular}{cccccc}
\hline DMUs & $\begin{array}{c}\boldsymbol{Y}^{*} \\
\text { in Model }(\mathbf{9})\end{array}$ & $\begin{array}{c}\text { Output } \\
\left(\boldsymbol{O}_{\mathbf{1}}\right)\end{array}$ & $\begin{array}{c}\text { Maximum revenue } \\
\text { Model } \mathbf{( 9 )}\end{array}$ & $\begin{array}{c}\text { Current revenue } \\
\text { Eq. (8) }\end{array}$ & $\begin{array}{c}\text { PL-RE } \\
\text { Eq. (10) }\end{array}$ \\
\hline 1 & 7000000 & 3297100 & 15600000000 & 3356400000 & 0.4 \\
8 & 7067354 & 4341330 & 4609596000 & 4609596000 & 0.541 \\
11 & 1100000 & 11000000 & 15600000000 & 15600000000 & 1 \\
13 & 7196540 & 7196540 & 8753772000 & 8753772000 & 1 \\
15 & 700327277 & 5621431 & 6332146500 & 6332146500 & 0.75 \\
\hline
\end{tabular}

Table 14. The results of the classical approach.

\begin{tabular}{cccccc}
\hline \multirow{2}{*}{ DMUs } & $\begin{array}{c}\boldsymbol{Y}^{*} \\
\text { in Model (2) }\end{array}$ & $\begin{array}{c}\text { Output } \\
\left(\boldsymbol{O}_{\mathbf{1}}\right)\end{array}$ & $\begin{array}{c}\text { Maximum revenue } \\
\text { Model (2) }\end{array}$ & $\begin{array}{c}\text { Current revenue } \\
(\mathbf{W Y )}\end{array}$ & $\begin{array}{c}\text { RE } \\
\text { Eq. (3) }\end{array}$ \\
\hline 1 & 3700169 & 3297100 & 3700169133 & 3297100000 & 0.891 \\
8 & 4816983 & 4341330 & 4816983946 & 4341330000 & 0.901 \\
11 & 1100000 & 11000000 & 11000000000 & 11000000000 & 1 \\
13 & 8307347 & 7196540 & 8307347694 & 7196540000 & 0.866 \\
15 & 5702484 & 5621431 & 5702484640 & 5621431000 & 0.985 \\
\hline
\end{tabular}

from those of the classical model. Furthermore, the progress and regress of DMUs were discussed that gave important implications to managers for making crucial decisions.

In Tables 13 and 14, the results of Models (9) and (2) for DMUs 1, 8, 11, 13, and 15 are reported, respectively. Given Tables 13 and 14, it is clear that our model (Model (9)) in most of the DMUs increases the output compared with Model (2). At the upper intervals, since higher prices are considered, our model tries to reach higher amounts. The maximum revenue obtained from Model (9) is higher than that from Model (2). This is an important finding for managers as they are responsible for performance evaluation. 
Another important finding is the RE score that may decrease, increase, or remain unchanged. This shows the different capability of DMUs for producing products according to the stepwise pricing.

\section{Conclusions}

This study modified the classical Revenue Efficiency (RE) in Data Envelopment Analysis (DEA). The classical RE in DEA had two critical issues. Firstly, its linear pricing could not show the reality of variables with a nonlinear behavior. Secondly, the classical RE assumed the fixed prices not being applicable to realworld problems. This research employed DEA for evaluating the RE and addressed the shortcomings. Our model dealt with stepwise pricing systems to get more accurate results in $\mathrm{RE}$ assessments. We demonstrated that the results might increase, decrease, or remain unchanged compared with the previous $\mathrm{RE}$ models. Decision-Making Units (DMUs) could produce more products with higher prices to get more revenues. For further researches, we suggest developing new DEA models that can deal with competitive settings. Finding an optimal value of the big $M$ will be another interesting research topic.

\section{Acknowledgments}

Authors would like to thank the constructive comments of two anonymous reviewers.

\section{References}

1. Farell, M.J. "The measurement of productive efficiency", J. R. Statist. Soc., 120(3), pp. 253-281 (1957).

2. Charnes, A., Cooper, W.W., and Rhodes, E. "Measuring the efficiency of decision-making units", Eur. J. Oper. Res., 2(6), pp. 429-444 (1978).

3. Kuosmanen, T. and Post, T. "Measuring economic efficiency with incomplete price information: With an application to European commercial banks", Eur. J. of Oper. Res., 134, pp. 43-58 (2001).

4. Kuosmanen, T. and Post, T. "Measuring economic efficiency with incomplete price information", Eur. J. of Oper. Res., 144(2), pp. 454-457 (2003).

5. Mostafaee, A. and Saljooghi, F. "Cost efficiency measures in data envelopment analysis with data uncertainty", Eur. J. of Oper. Res., 202(2), pp. 595-603 (2010).

6. Chakraborty, T., Chauhan, S.S., Awasthi, A., et al. "Two-period pricing and ordering policy with price sensitive uncertain demand", J. of Oper. Res. Soci., 70(3), pp. 377-394 (2018).

7. Fang, L. and Li, H. "A comment on cost efficiency in data envelopment analysis with data uncertainty", Eur. J. of Oper. Res., 220(2), pp. 588-590 (2012).
8. Mozaffari, M., Kamyab, P., Joblonsky, J., et al. "Cost and revenue efficiency in DEA-R models", Comp. Indus. Eng., 78, pp. 188-194 (2014).

9. Ghiyasi, M. "Inverse DEA based on cost and revenue efficiency", Comp. \& Indus. Engin., 114, pp. 258-264 (2017)

10. Fang, L. and Hecheng, Li. "Duality and efficiency computations in the cost efficiency model with price uncertainty", Comp. \& Oper. Res., 40(2), pp. 594-602 (2013).

11. Aparicio, J., Borras, F., Pastor, J.T., et al. "Accounting for slacks to measure and decompose revenue efficiency in Spanish designation of origin wines with DEA", Eur. J. Oper. Res., 231(2), pp. 443-451 (2013).

12. Sahoo, B.K, Mehdillozad, M., and Tone, K. "Cost, revenue, and profit efficiency measurement in DEA", Eur. J. Oper. Res., 237(3), pp. 921-931 (2014).

13. Aparicio, J., Borras, F., Pastor, J.T., et al. "Measuring and decomposing firm's revenue and cost efficiency: The Russell measures revisited", Int. J. Production Economics., 165, pp. 19-28 (2015).

14. Cook, D.W. and Zhu, J. "Piecewise linear output measure in DEA", Eur. J. Oper. Res., 197(1), pp. 312319 (2009).

15. Hosseinzadeh Lotfi, F.H., Rostamy-Malkhalifeh, M., and Moghaddas, Z. "Modified piecewise linear DEA model", Eur. J. Oper. Res., 205(3), pp. 729-733 (2010).

16. Konara, P., Tan, Y., and Johnes, J. "FDI and heterogeneity in bank efficiency: Evidence from emerging markets", Res. Int. Bus. Finance, 49(c), pp. 100-113 (2019).

17. Deng, Y., Veiga, H., and Wiper, M.P. "Efficiency evaluation of hotel chains: a Spanish case study", SERIEs, 10(2), pp. 115-139 (2019).

18. Cao, Y., Zhang, W., and Ren, J. "Efficiency analysis of the input for water-saving agriculture in China", Water, 12(1), p. 207 (2020).

19. Aroche-Reyes, F. "Endogenous prices for input/output models: A note", Economic Systems Research, 5(4), pp. 365-376 (2006).

20. Johnson, A.L. and Ruggiero, J. "Allocative efficiency measurement with endogenous prices", Econ. Letters, 111(1), pp. 81-83 (2011).

21. Moura, A. "Investment shocks, sticky prices, and the endogenous relative price of investment", Rev. of Econ. Dynam., 27, pp. 48-63 (2018).

22. Din, H. and Sun, C.H. "Welfare improving licensing with endogenous choice of prices versus quantities", North Amer. J. of Econ. and Fina., 51(c), p. 100859 (2020). 
23. Cellini, R., Siciliani, L., and RuneStraume, O. "A dynamic model of quality competition with endogenous prices", J. of Econ. Dynam. and Contr., 94(c), pp. 190-206 (2018).

24. Cooper, W.W., Seiford, L.M., and Tone, K., Data Envelopment Analysis, A Comprehensive Text with Models, Applications, References and DEA-Solver Software, Second edition, Springer (2007).

25. Wang, C.G., Fare, R., and Seavert, C.F. "Revenue capacity efficiency of pear trees and its decomposition", J. Amer. Soci. for Horticultural Sci., 131(1), pp. 32-40 (2006).

26. Caves, D.W., Christensen, L.R., and Diewert, W.E. "The economic theory of index numbers and the measurement of input, output and productivity", $J$. Econometrica, 50(6), pp. 1393-1414 (1982).

27. Tavanir Management Organization, Electric Power Industry in Iran 1997-2004 (2015).

\section{Biographies}

Zohreh Moghaddas is an Assistant Professor at the Department of Mathematics, Qazvin Branch, Islamic Azad University, Qazvin, Iran. Her research interests include mathematical modeling, optimization, operations research, and data envelopment analysis.

Mohsen Vaez-Ghasemi is an Assistant Professor at the Department of Mathematics, Rasht Branch, Islamic Azad University, Rasht, Iran. His research interests include supply chain management, optimization, metaheuristic algorithms, operations research, and data envelopment analysis.

Farhad Hosseinzadeh Lotfi is a Full Professor at the Department of Mathematics, Science and Research Branch, Islamic Azad University, Tehran, Iran. His research interests include applied mathematics, mathematical modelling, operations research, optimization, data envelopment analysis, MCDM, and fuzziness.

Reza Farzipoor Saen has published over 192 refereed papers in ABDC and ABS ranked journals. His $h$ indices in Google Scholar and Scopus are 41 and 37 , respectively. He has 24 years of industrial and consultation experience. Dr. Farzipoor is on the list of top $2 \%$ of scientists in the world, ranked by Stanford University (2020; 2021). 